\title{
Possible role of auroral oval-related currents in two intense magnetic storms recorded by old mid-latitude observatories Clementinum and Greenwich
}

\author{
Fridrich Valach ${ }^{1, *}$, Pavel Hejda ${ }^{2}$, Miloš Revallo ${ }^{3}$, and Josef Bochníček ${ }^{2}$ \\ ${ }^{1}$ Geomagnetic Observatory, Earth Science Institute, Slovak Academy of Sciences, Komárňanská 108, 94701 Hurbanovo, Slovakia \\ 2 Institute of Geophysics, Academy of Sciences of the Czech Republic, Boční II/1401, 14131 Prague, Czech Republic \\ ${ }^{3}$ Earth Science Institute, Slovak Academy of Sciences, Dúbravská cesta 9, 84005 Bratislava, Slovakia
}

Received 3 December 2018 / Accepted 28 February 2019

\begin{abstract}
Some recent studies point out that currents related to the auroral oval, electrojets and field aligned currents (FACs), are serious candidates for the mechanism of the intense mid-latitude magnetic storms. It is interesting to re-analyse historical data under the light of this modern knowledge. In this aim, we analysed two intense magnetic storms that were recorded by observatories Clementinum (Prague) and Greenwich on 17 November 1848 and 4 February 1872, respectively. The latter has been marked as an extraordinary event by several authors, in particular in connection with auroras. The former, however, has been little known in the space weather community. Both these events possessed swift and extensive variations of the horizontal $(H)$ component (>400 $\mathrm{nT}$ and $>500 \mathrm{nT}$, respectively) and were accompanied by auroras sighted at very low magnetic latitudes. This implies that the auroral oval on the north hemisphere was vastly extended southward. The variations of the magnetic declination also indicate that during these events the auroral oval was situated at magnetic latitudes lower than those of the observatories. The storms studied in this paper occurred at different magnetic local times (MLTs), 23 MLT and 19 MLT. Therefore, they might represent mid-latitude events related to different parts of the auroral oval. In this paper, the $H$-variation recorded at Clementinum in 1848 is interpreted to be a substorm due to the ionospheric substorm electrojet. The Greenwich event registered in 1872 then seems to be a combination of the ring-current storm with a positive variation of the $H$-component caused by the eastward electrojet. Both the events of 1848 and 1872 appear to exemplify phenomena that are common in high magnetic latitudes but which may occasionally happen also at mid-latitudes.
\end{abstract}

Keywords: storm / substorm / geomagnetism / extreme events / historical records

\section{Introduction}

Traditional concepts of the mid- and low-latitude geomagnetic disturbances emphasise that the most important geomagnetic variations are the geomagnetic storms that are caused by the enhanced ring current. The most intense amongst the so far recorded magnetic storms has likely been the Carrington storm of 2 September 1859, during which the horizontal component $(H)$ dropped at Colaba (Bombay) by $1600 \mathrm{nT} \pm 10 \mathrm{nT}$ (Tsurutani et al., 2003). It commenced $\sim 17 \mathrm{~h}$ and $40 \mathrm{~min}$ after the extraordinary solar flare that occurred on 1 September 1859 (Carrington, 1860; Hodgson, 1860). It is highly probable that at

*Corresponding authr: fridrich@geomag. sk the time of the flare occurrence a fast coronal mass ejection (CME) was launched towards the Earth. Green and Boardsen (2006) even suggested that on 2 September 1859 the Earth was hit by two closely spaced CMEs. Tsurutani et al. (2003) proposed that the interaction of the planetary magnetosphere with a geoeffective magnetic cloud within the CME (or CMEs) led to increase of the total energy of the ring current particles. Consequently, the depression of the $H$-component was observed at the Colaba Observatory.

On the other hand, it is also known that much more violent geomagnetic field variations than the ring-current storms commonly happen, too. These latter variations, called auroral substorms, tend to occur at high magnetic latitudes (e.g., Akasofu \& Chapman, 1964). Interestingly, however, it has been shown 
that the intensity of auroral substorms, when identified based on the geomagnetic variations, grow towards the equator (Tanskanen et al., 2002).

Though the Carrington storm was initially interpreted as a ring-current storm (Tsurutani et al., 2003), an alternative interpretation of this noteworthy event has recently been presented by Cid et al. (2015). A need for an alternative concept stemmed from the rapid recovery phase of the Carrington storm, when during ca $2 \mathrm{~h}$ the magnetic field recovered by more than 1300 nT (Keika et al., 2015). This rapidity seemed to be inconsistent with the mechanism of the ring current decay. Therefore, Cid et al. (2015) proposed that the Carrington storm was due to field aligned currents (FACs). An important factor in this new interpretation is the magnetic local time (MLT) of the event, which was $2-10$ MLT, because the occurrence of a specific FAC depends on it. The authors built their interpretation on the analysis of the FACs (Shi et al., 2008), in which the Tsyganenko storm time magnetic field model TS04 (Tsyganenko \& Sitnov, 2005) was utilised. This analysis yielded an overall picture of the $H$ and $D$ (magnetic declination) variations due to the net FAC system. Thus even in midlatitudes the current system that is connected to the auroral oval might occasionally cause prominent geomagnetic variations that measure up to the ring-current storms. They sometimes happen at mid-latitudes, despite such currents (westward, eastward and substorm electrojects and FACs) are typical for high magnetic latitudes which are the common setting for the auroras.

Indeed, during the Carrington storm the auroras were seen at unusually low magnetic latitudes at Hawaii and Santiago $\left(\sim 23^{\circ} \mathrm{N}\right)$ (Tsurutani et al., 2003). Using information on the polar lights, Moreno Cárdenas et al. (2016) estimated that the auroral oval of the north hemisphere reached Colombia and the north edge of Africa. Whole Europe and the major part of Asia lay within the area surrounded by the auroral oval in the time of the storm of 2 September 1859. Such an expansion of the oval requires special conditions in the ambient space environment, when the interplanetary magnetic field with a largely negative north-south component extends southward for a long time (Tanskanen et al., 2005). Those conditions lead to intensification of magnetospheric and auroral current systems and cause the polar cap widening.

Also Green and Boardsen (2006) pointed out the proximity of the auroral oval to Bombay during the Carrington event. They concluded that the dominating part of the magnetic field perturbation measured in Colaba might have been caused by currents in the nearby auroral electrojet.

Historical records of the geomagnetic events such as that of the Carrington storm may provide interesting information on unique geomagnetic variations in the past. This study presents two other events of the 19th century, which in our opinion illustrate the importance of the non-ring-current variations in mid-latitudes. They were reported in the yearbooks of observatories Clementinum (Prague) (Kreil \& Jelinek, 1850) and Greenwich (Airy et al., 1874) on 17 November 1848 and 4 February 1872, respectively. The events of Clementinum, Colaba (Carrington storm) and Greenwich occurred in three successive solar cycles, namely 9, 10 and 11. They took place at different MLTs and we believe that they document interesting mid-latitude geomagnetic variations at three different places related to the auroral oval.
Table 1. The coordinates of observatories Clementinum and Greenwich according to information on the web page of the International Service of Geomagnetic Indices. The geomagnetic latitude and longitude are the corrected geomagnetic coordinates referred to epoch 2015.5.

\begin{tabular}{llcc}
\hline \multicolumn{2}{c}{ Coordinates } & Clementinum & Greenwich \\
\hline Geographic & Latitude & $50.08^{\circ} \mathrm{N}$ & $51.48^{\circ} \mathrm{N}$ \\
& Longitude & $14.42^{\circ} \mathrm{E}$ & $00.00^{\circ} \mathrm{E}$ \\
Geomagnetic & Latitude & $49.42^{\circ} \mathrm{N}$ & $53.18^{\circ} \mathrm{N}$ \\
& Longitude & $98.50^{\circ} \mathrm{E}$ & $84.96^{\circ} \mathrm{E}$ \\
Altitude & & $200 \mathrm{~m}$ & $50 \mathrm{~m}$ \\
\hline
\end{tabular}

\section{The historical records}

This paper studies the events of 17 November 1848 and 4 February 1872, which were recorded by the observatories Clementinum (Prague, IAGA Code ${ }^{1}$ PRA) and Greenwich (IAGA Code GRW), respectively. The coordinates of the observatories according to information on the web page of the International Service of Geomagnetic Indices ${ }^{2}$ are stored in Table 1.

The following sections describe the events in line with the historical records of Clementinum and Greenwich. The description of the event of 1872 is supplemented by additional information about the profile of the horizontal intensity that was recorded by Colaba (Bombay), the low-latitude observatory with the magnetic latitude $10.75^{\circ} \mathrm{N}$.

At that date, Gauss' bifilar magnetometer (Gauss, 1838) was employed for the measurements of the $H$-component variations. The description of this old-time device, which is not very well known nowadays, can be found in Garland (1979), Nevanlinna (1997). The main part of such an instrument was a huge magnetic needle suspended by two long metal threads separated by a short distance apart. The needle was only free to move in the horizontal plane, usually measured almost one metre and weighed about two kilograms. The metal threads were a few metres long and were typically several centimetres apart. In order to adjust the instrument, a torsion head located at the top of the suspension was revolved till the needle was at right angles to the magnetic meridian. In order to achieve this perpendicular position of the needle, starting from the initial position when the needle aligned with the direction of the $H$-component, the torsion head needed to be revolved by angle $\psi$. The adjusted instrument was then used for reading small changes on the orientation of the needle, from which the small changes of $H$ could be determined by means of the following equation

$$
\frac{\Delta H}{H_{0}}=\epsilon_{H} \tan (\psi)\left(h-h_{0}\right)+\alpha\left(t-t_{0}\right),
$$

where $\Delta H$ and $H_{0}$ stand for the variation of the $H$-component and the absolute base-value of the $H$-component, respectively. On the right-hand side of the equation, $\epsilon_{H}$ is the optical scale value for the mirror-and-scale method, which was commonly

\footnotetext{
${ }^{1}$ An identification code assigned to a magnetic station by the International Association of Geomagnetism and Aeronomy (IAGA).

${ }^{2}$ Information about observatories PRA (Prague, Clementinum) and GRW (Greenwich) is available on the web pages http://isgi.unistra. fr/observatory.php?obs=PRA and http://isgi.unistra.fr/observatory. php?obs=GRW, respectively.
} 
in use for determining the orientation of the needle in angular units. Furthermore, $h$ is the reading of the orientation of the needle (scale value), $h_{0}$ is the scale base-value, $\alpha$ is a temperature coefficient, and $t-t_{0}$ is the difference between the current temperature and a chosen reference temperature. For detailed derivation of this formula see Nevanlinna (1997). For the data of Clementinum on 17 November 1848 (Sect. 2.1), the last term in Equation (1) is taken zero because the massive building of that observatory assured constant temperature during the magnetic storm. Similarly, the data of the storm on 4 February 1872 from observatory Greenwich (Sect. 2.2) are uncorrected for temperature. The variations of the magnetic field during the storm were so large and rapid that the temperature corrections were needless.

The time recorded in the original yearbooks is given in Göttingen Mean Solar Time (MST) for the event of 1848 (Kreil $\&$ Jelinek, 1850) and Greenwich Mean Solar Time for the event of 1872 (Airy et al., 1874). For the study of the geomagnetic activity it is convenient to have these time records converted to the MLT. ${ }^{3}$ For this purpose we used the standard procedure, which is described in Montbriand (1970). The data for this procedure were taken from Table 1 and all the MLTs in this study are thus referred to the 2015.5 epoch. Based on the known change of magnetic coordinates at Greenwich and Clementinum since the year 1900, an approximately 10-minute difference can be expected between the present-day MLTs and those of the 19 th century. It is supposed in this study that such an inaccuracy does not affect the interpretation outlined in Section 3.

\subsection{Data of Clementinum on 17 November 1848}

In this section, unique geomagnetic data are shown, which to our knowledge are almost unknown among the geomagnetic and space weather community. The source of these data is the yearbook of the Clementinum observatory for the year 1848 (Kreil \& Jelinek, 1850). For the geomagnetic event of 17 November 1848, the courses of horizontal intensity and magnetic declination are tabulated in this source.

Because the aforementioned bifilar magnetometer produced values expressed in parts of the whole horizontal force (Eq. (1)), Kreil and Jelinek (1850) used also Gauss's absolute method (e.g., Van Baak, 2013) in order to obtain the value of this whole horizontal force. According to the yearbook, during the days 4 to 11 April 1848 they performed 11 absolute measurements, the average value of which being $18812.4 \mathrm{nT}$. The dispersion of their data expressed by means of the standard deviation was $\pm 24.9 \mathrm{nT}$ and the data ranged from $18778 \mathrm{nT}$ to $18852 \mathrm{nT}$. According to the magnetic field calculator which is available on the web page of National Oceanic and Atmospheric Administration (NOAA), ${ }^{4}$ the $H$ for Prague was then 18819.5 nT. This perfectly confirms the reliability of the measurements made by Kreil and Jelinek (1850). In the following, we take their value, i.e., $18812.4 \mathrm{nT}$.

The variation of the declination and horizontal intensity recorded at Clementinum during the storm of 17 November

\footnotetext{
${ }^{3}$ The MLT is measured from the magnetic local midnight, whereas the local (e.g., Göttingen or Greenwich) mean solar time is measured from the local noon.

${ }^{4}$ The NOAA website with the magnetic field calculator is https:// www.ngdc.noaa.gov/geomag-web/\#igrfwmm.
}

1848 is shown in Figure 1. The maximum depression of the $H$-component was observed at 10:26 h of Göttingen Mean Solar Time, which corresponds to 23:20 MLT. The figure also shows that a local minimum of $D$ occurred simultaneously as the $H$-component depression. The variations of $D$ that go beyond the values displayed in the graph, one of them at 04:08 h $\left(-33.6^{\prime}\right)$ and the other at 18:00 $\mathrm{h}\left(-38.8^{\prime}\right)$, obviously have no direct relations with the depression of $H$. All recorded digital values of the horizontal intensity and declination since the noon of 17 November 1848 to the next noon are listed in Table A1 (Appendix).

At the time of the rapid variation, telegraph networks experienced unusually large voltages and simultaneously a great aurora was observed in Italy (Odenwald, 2015, p. 18). The sighting of the aurora at such low magnetic latitudes indicates that the auroral oval had to be expanded deep to south, far from its usual positions.

\subsection{Data of Greenwich on 4 February 1872}

Another noteworthy geomagnetic storm occurred on 4 February 1872, hence in the solar cycle that followed immediately after the cycle with the Carrington superstorm. The $H$-component observed at the low-latitude observatory Colaba, documents that the then ring-current storm was very intense (Fig. 2), the depression of $H$ being more than $700 \mathrm{nT}$. Including a rise in the magnetic field before the main phase of the storm, the range of $H$-values was even more than $900 \mathrm{nT}$. The data of Colaba for this event can be found in Moss (1910), which is accessible on the web page of the British Geological Survey.

The mighty auroras that occurred during this magnetic storm have been investigated by several researchers. Based on the study of these extraordinary phenomena, Hayakawa et al. (2018) likened the storm of 4 February 1872 to the Carrington storm. Silverman (2008) even claimed that the storm of 1872 was comparable or probably greater than the Carrington event. This claim is based on the fact that the north lights were observed at such low magnetic latitudes as $10^{\circ}$. Also Chapman (1953) wrote that on 4 February 1872 the aurora was sighted even in Bombay. Hayakawa et al. (2018) confirmed the above mentioned information on low-latitude observations of auroras on that period by investigation of historical records of northern lights in East Asia.

The profiles of the $H$-component and declination registered at Greenwich on 4 February 1872, displayed in Figure 3, were constructed from the data listed in Airy et al. (1874). Here, the extent of $H$-values was more than $800 \mathrm{nT}$ and the maximum depression of $H$ occurred at 06:57 of Greenwich Mean Solar Time, which corresponded to 19:42 MLT. Interestingly, the $H$-profile at the mid-latitude Greenwich was markedly distinct from the $H$-profile at the low-latitude Colaba. Unlike the Colaba profile, the horizontal intensity at Greenwich was considerably increased both before and after the maximum depression. This feature is more deeply studied in Section 3. The declination at Greenwich showed a local minimum before the $H$-component depression. However, when the $H$ depression appeared, the declination had already been returned to more disturbed values.

The time of the depression occurrence for $H$-profile at Colaba (Fig. 2) seems not to coincide with the instant when the $H$-depression appeared at Greenwich (Fig. 3). This is only 

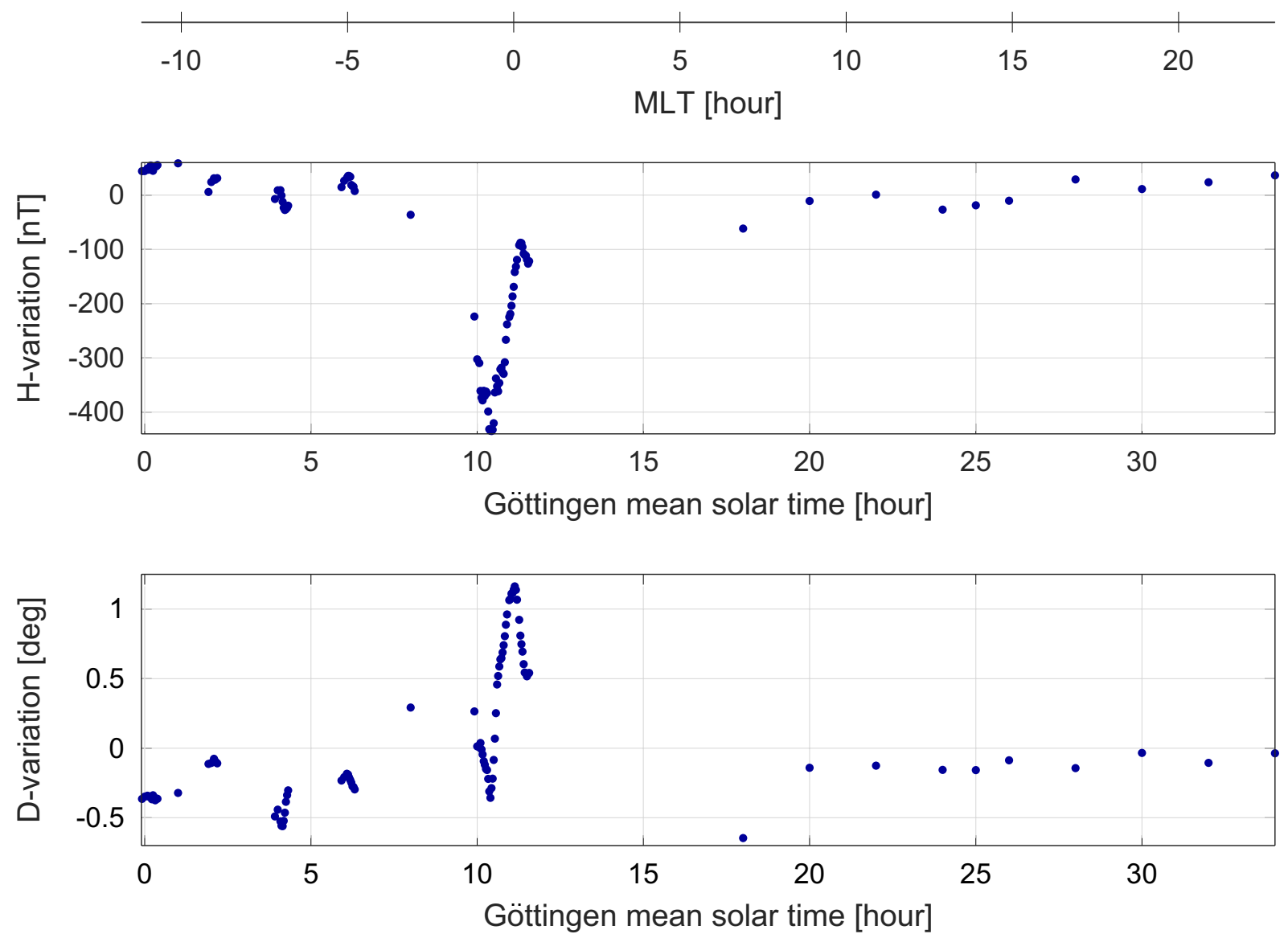

Fig. 1. The variations of the horizontal intensity and declination that were recorded at the Clementinum observatory on 17 November 1848 (Kreil \& Jelinek, 1850). The additional time axis at the top of the figure shows the magnetic local time (MLT).

\begin{tabular}{ccccc}
\hline & + & & \\
\hline-5 & 0 & 5 & 10 & 15
\end{tabular}

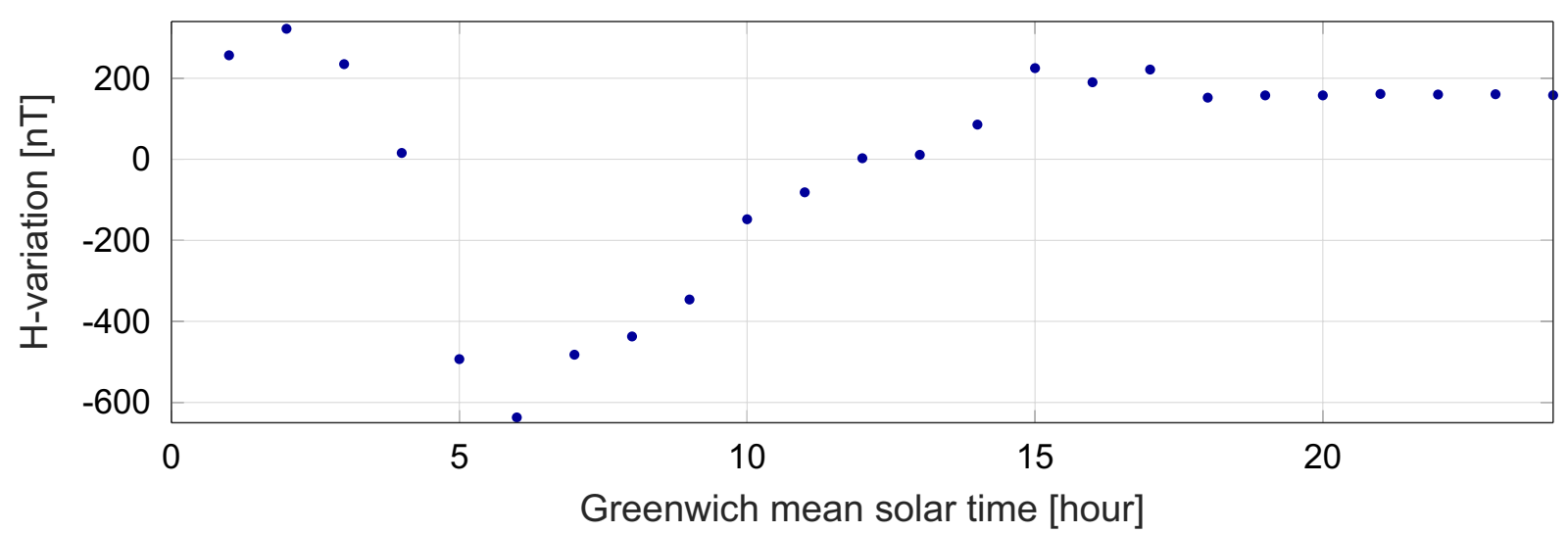

Fig. 2. The profile of the variations of the horizontal intensity during the magnetic storm of 4 February 1872 that was recorded by the low-latitude observatory Colaba (Bombay), India. The displayed values are 1-hour means. The additional time axis at the top of the figure shows the magnetic local time (MLT). 


\begin{tabular}{cccc}
\hline-10 & -5 & 0 & 1 \\
& MLT [hour] & & 10
\end{tabular}
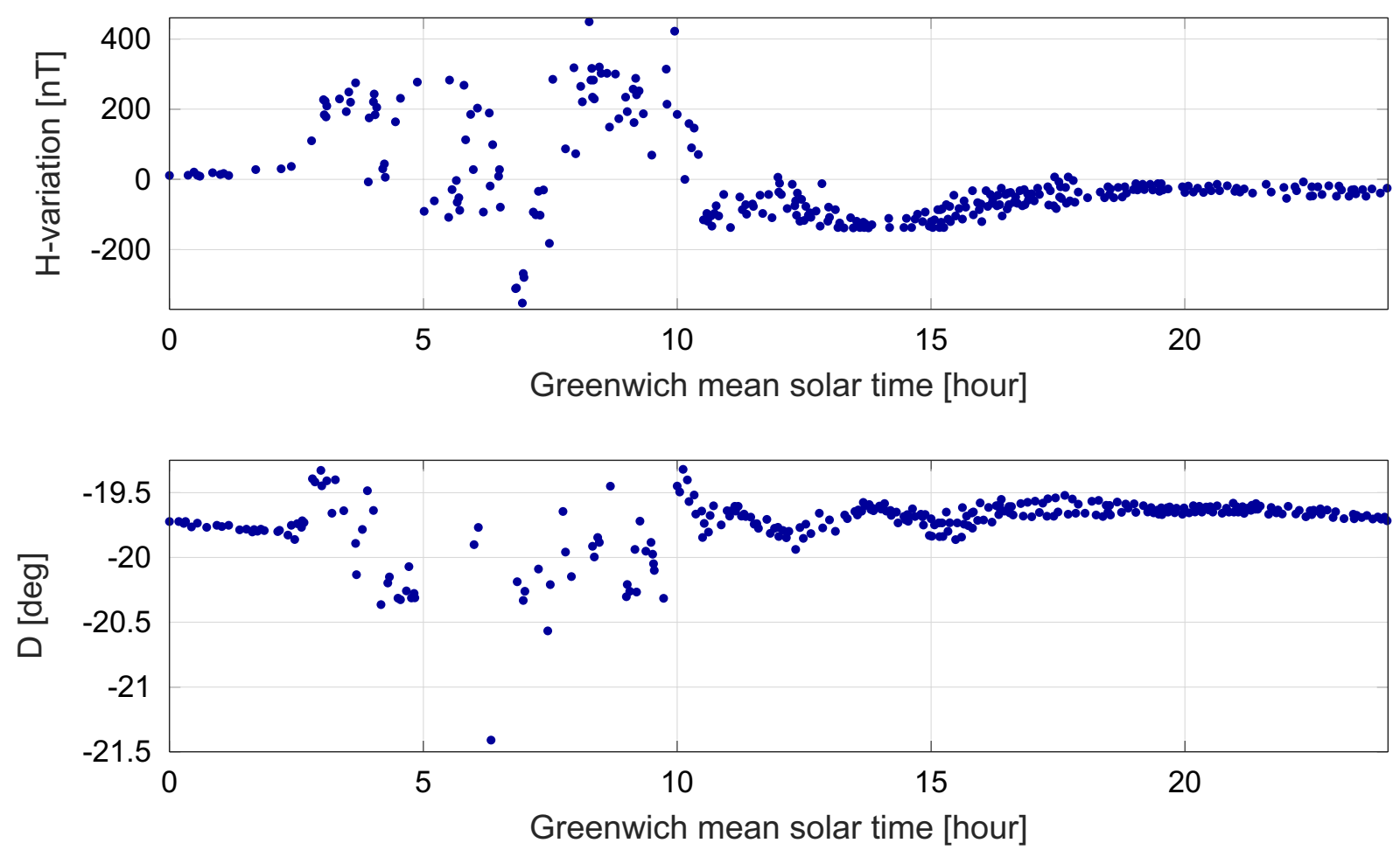

Fig. 3. The horizontal intensity and magnetic declination observed at Greenwich during the magnetic storm on 4 February 1872 . The baseline value for the horizontal intensity is $18000 \mathrm{nT}$. The additional time axis at the top of the figure shows the magnetic local time (MLT).

a disagreement that is due to different methods used for measurement and processing the data. On the one hand, the displayed data of Colaba are the excesses over the mean of the $\mathrm{H}$-component of the first $24 \mathrm{~h}$ after the commencement of the storm. Their values were likely assessed from the analogue magnetogram recorded by an automated magnetometer. The values assigned to particular hours were determined for 1-hour segments of the magnetogram which covered the period from the respective exact hour to the last instant before the next exact hour. On the other hand, the data shown for Greenwich are the data "at punctum temporis", i.e., they were manually read from the bifilar instrument by the observers and are relevant to the exact time mark. The deep minimum in the $H$-profile at Greenwich appeared right before 07:00 $\mathrm{h}$, which fell into the 1-hour mean marked as 06:00 h. This explains the false 1-hour discrepance in the instant of the $H$-minimum at Colaba and Greenwich.

\section{Discussion}

This section discusses the relationships between the above mentioned data and some currents related to the auroral oval, namely the eastward electrojet, (ionospheric) substorm electrojet and FACs. The idea is somewhat similar to the reasoning of Cid et al. (2015) behind their analysis of the Carrington event. The outline of possible connections with the FACs is based on the distribution of net FACs that Shi et al. (2008) inferred from the $D$ perturbations observed during the magnetic storm of 25 September 1998. The authors used the data of 64 stations situated both inside and outside the auroral oval and visualised the positions and qualitative strengths of the upward and downward net FACs in a polar plot. That case study provides also a polar plot for variations of the horizontal component. However, an important issue has to be stressed when studying the variations of $H$ in relation to the currents described by Shi et al. (2008); these authors dealt with $H$-profiles from observatories that were situated far from the auroral oval. In their case, the $H$-profiles were not affected significantly by the geomagnetic variations due to electrojets of the auroral oval and the authors were interested exclusively in the FACs. But in our two cases, we consider the situations in which the auroral oval on the north hemisphere was vastly extended to south, and hence to low magnetic latitudes. In the events of Clementinum and Greenwich presented in this study the influence of the electrojects cannot be neglected. In contrast, they might play essential roles.

\subsection{The interpretation of the Clementinum record of 17 November 1848}

In this section, we interpret the record of the geomagnetic variation from Prague (Clementinum), which was described in Section 2.1. For the study of the geomagnetic variations due 


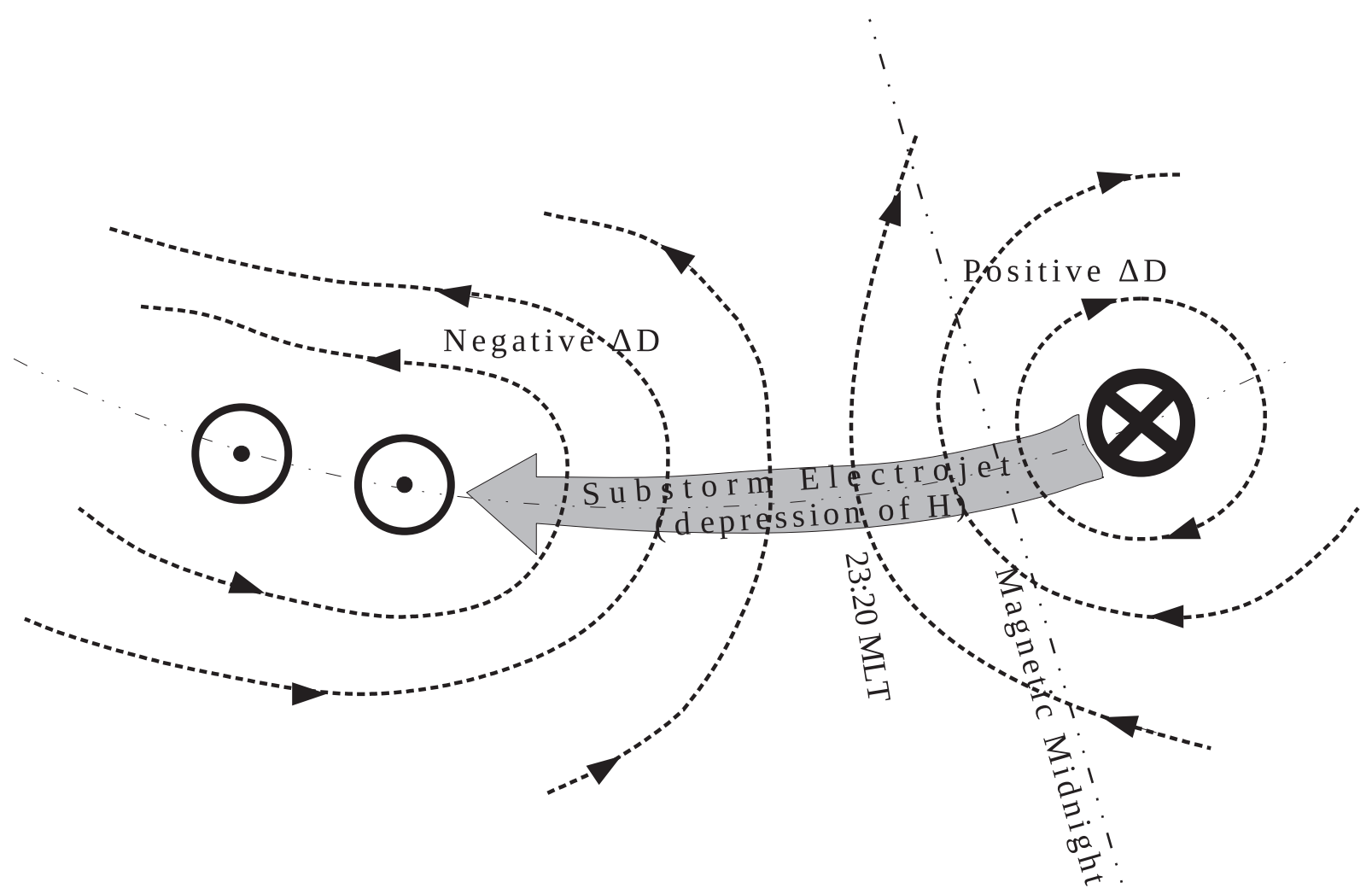

Fig. 4. The schematic sketch of the conditions of the Clementinum observatory during the magnetic storm on 17 November 1848 . The circles with dots in their centres indicate the location of the upward FAC, the circle with a cross mark the position of the downward FAC. The intensity of the electric currents is expressed by means of the boldness of the markers. The dashed lines represent the lines of force of the magnetic field generated by the FACs. The $\Delta D$ sign stands for the deviation of the magnetic declination. We suppose that the substorm electrojet then flowed at a magnetic latitude which was lower than the magnetic latitude of Clementinum.

to an electrojet, one has to focus on the variations of the $H$-component. In order to study the variations due to the FACs, the declination has to be investigated, too. Figure 4 shows a schematic sketch of the substorm electrojet and FACs which we consider to be the source of the geomagnetic variations during the Clementinum event.

Unfortunately, the observations of $H$ at the Clementinum did not capture the whole course of the event. The beginning of the $H$-depression was not registered in Kreil and Jelinek, (1850). The parts of the storm which were captured were: (1) the second part of the drop of $H$-component and (2) the whole rapid recovery. The recorded variation of the horizontal intensity was very swift and hence in our considerations we excluded the ring current as its origin. The duration of the variation is typical for another well-known geomagnetic variation - the substorm. Therefore, we interpret the variation at Clementinum to be likely a substorm due to the substorm electrojet. Another argument which supports our interpretation is the local magnetic time of the maximum of the $H$-depression (23:20 MLT), which suggests that the depression was caused by the substorm electrojet. We assume that because of the immediate vicinity of the substorm electrojet, the $H$-depression predominate over the positive variation which should be generated by FACs. In consequence, the presence of such a positive variation in $H$-component is not evident in Figure 1.
The variation of $D$ may indicate the position of the observatory with respect to the auroral oval or, more specifically, to the substorm electrojet. The shape of this variation resembles a sine curve: at first, $D$ shows a swift downturn under a normal value, after that it quickly increases over that value. With the help of Figure 4, we can deduce that during the violent variation the observatory was situated inside the auroral oval. That means the substorm electrojet flowed at a lower magnetic latitude than is the magnetic latitude of the observatory.

\subsection{The interpretation of the Greenwich record of 4 February 1872}

The gross image about the situation during the event of 1872 recorded at Greenwich observatory is sketched in Figure 5. It appears that in this case there is a common ring-current storm superimposed onto a several-hour-lasting positive variation of the $H$-component. During this positive variation, which lasted from ca $03: 00 \mathrm{~h}$ to ca 10:15 $\mathrm{h}$, the horizontal intensity rose by ca $200 \mathrm{nT}$. The likely cause of this rise is the eastward electrojet. It is highly probable that the eastward electrojet, which then strongly affected the $H$-profile at Greenwich, was situated close to the observatory on 4 February 1872.

The $H$-variation reached its extreme shortly before 07:00 h at Greenwich, the corresponding MLT being 19:42 MLT. 


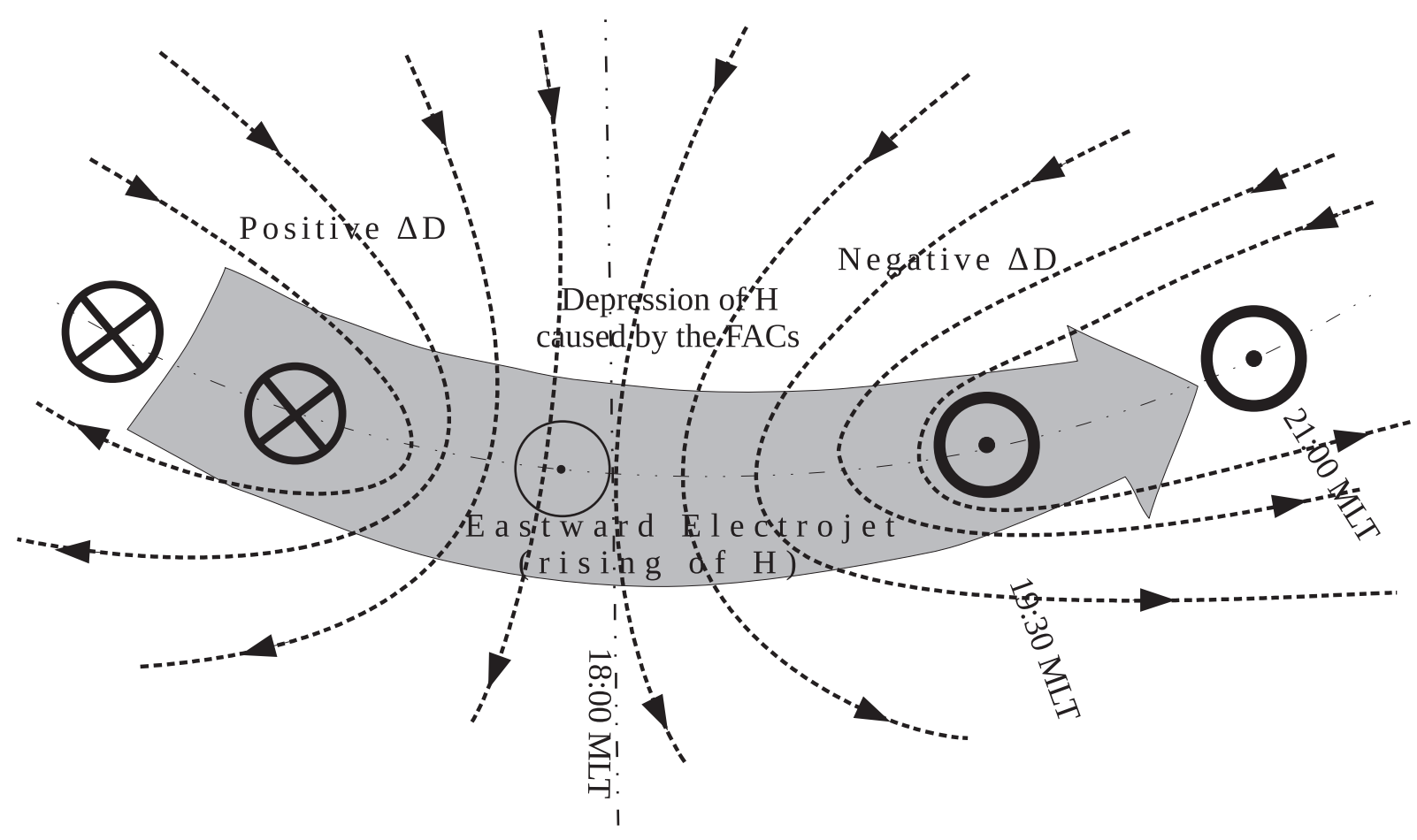

Fig. 5. The sketch of the situation during the geomagnetic storm at Greenwich on 4 February 1872 . The circle with the dots in their centres indicate the position of the FAC flowing upward, the circles with crosses mark the FAC flowing downward. The boldness of the marks expresses the intensity of the electric currents. The dashed lines represent the lines of force of the magnetic field that is generated by the FACs. The $\Delta D$ sign stands for the deviation of the magnetic declination. Here we assume that the eastward electrojet flowed at lower magnetic latitudes than is the magnetic latitude of Greenwich.

This extreme in the Greenwich data appeared simultaneously with the maximum depression at Colaba. Such a coincidence implies that this drop in $H$ had its origin in the intensification of the ring current. The less noticeable drop of $H$ between 05:00 $\mathrm{h}$ and $05: 30 \mathrm{~h}$ as well as the decrease of $D$ between 06:00 $\mathrm{h}$ and 07:00 $\mathrm{h}$ might be caused by the FACs. Here we assume that the observatory was situated slightly north of the eastward electrojet. It is reasonable to expect that if $D$ had been recorded in the period between 04:50 $\mathrm{h}$ and 06:00 $\mathrm{h}$, that record would have shown a positive variation of $D$. This expectation comes from the configuration of FACs (Fig. 5).

Finally, we can compare the intensity of the magnetic storm at Colaba and Greenwich. As noted previously (Sect. 2.2), the variation of the $H$-values exceeded $900 \mathrm{nT}$ for Colaba and $800 \mathrm{nT}$ for Greenwich. However, this is only a very rough comparison because, as we also mentioned in Section 2.2, the data of Colaba are 1-hour means, so they are somewhat smoothed. If this had not been the case, the data of Colaba would have possessed even larger extent than stated above. Nonetheless, the most violent part of the $H$-profile at Greenwich might be more rapid than the depression at Colaba as the course of $H$ was modified by the electrojet as well as FACs.

\section{Conclusions}

In this study we interpreted two geomagnetic storms that were registered by observatories Clementinum (Prague) and Greenwich on 17 November 1848 and 4 February 1872, respectively. The storm of 1872 has been marked as an extraordinary event by several authors, in particular in connection with auroras (e.g., Chapman, 1953; Silverman, 2008; Hayakawa et al., 2018). The magnetic storm of 1848 has not yet been generally known in the space weather community hence we list the digital data of this event in Appendix. Together with the Carrington event of 2 September 1859, the presented events constitute an interesting triad of phenomena. They were observed at three different MLTs and thus at three different sectors of the auroral oval. We assume that their mechanisms had connection with electrical currents of the auroral oval and corresponding FACs.

The events of 1848 and 1859 possessed rapid and deep depressions of the $H$-component. They were so deep, indeed, (more than $400 \mathrm{nT}$ and ca $1600 \mathrm{nT}$, respectively) that they competed with the most intense mid-latitude ring-current magnetic storms. But their mechanisms were not identical, the former of the $H$ depressions was probably due to the substorm electrojet (Fig. 4) while the latter depression was caused by FACs (Cid et al., 2015).

The event of 1872 had a bit more complicated $H$-profile than the previous two events. The rise of $H$ by more than 200 nT set in during this storm, which we ascribe to the eastward electrojet (Fig. 5). During the interval of the risen horizontal intensity, an inconspicuous short-time drop of $H$ by more than $350 \mathrm{nT}$ occurred at 05:00 h, which might be caused by FACs. The following significant depression, though smaller than the corresponding depression at the low-latitude Colaba, was the ring-current storm. However, at Greenwich this 
variation seems to be modulated by currents flowing in the auroral area, which might cause that the variation was more rapid than that of Colaba. The whole event ended with an abrupt decrease of $H$ by more than $500 \mathrm{nT}$ within a half of hour. This happened when the observatory got away from the influence of the eastward electrojet or when the electrojet ceased. The latter alternative might occur if the physical conditions in the nearEarth space changed, especially if the orientation of the interplanetary magnetic field changed from south to north.

The events studied in this paper were also characterised by sharp and rather large variations of magnetic declination, namely approximately a degree per half an hour. Thus, besides the geomagnetically induced currents, these events can affect the accuracy of the navigation for users of the magnetic compass.

Studying the Carrington event, Cid et al. (2015) concluded that the currents related to the auroral oval (the authors mentioned FACs) are serious candidates for the mechanism of the intense mid-latitude storms. The presented analysis of events of 17 November 1848 and 4 February 1872 supports the conclusion of these authors.

Acknowledgements. This work was supported in part by the grant no. VEGA-2/0002/17 of the Scientific Grant Agency of the Ministry of Education of Slovak Republic and the Slovak Academy of Sciences and by the grant no. GA17-19877S of the Czech Science Foundation. We thank the International Service of Geomagnetic Indices for keeping basic information on historical observatories on their web page. The authors also acknowledge the British Geological Survey for making accessible the geomagnetic yearbooks on their website (http://www. geomag.bgs.ac.uk/data_service/data/yearbooks/yearbooks. html).

\section{References}

Airy GB, Glaisher J, Nash WC. 1874. Results of the magnetical and meteorological observations made at the royal observatory, greenwich, 1872. Royal Observatory, Greenwich, UK. Retrieved from http://www.geomag.bgs.ac.uk/data_service/data/yearbooks/ YBpdf/YB_GRW_1872.pdf.

Akasofu S-I, Chapman S. 1964. On the asymmetric development of magnetic storm field in low and middle latitudes. Planet Space Sci 12(6): 607-626.

Carrington RC. 1860. Description of a singular appearance seen in the Sun on September 1, 1859. Mon Not Roy Astron Soc 20: $13-14$.

Chapman S. 1953. Polar and tropical auroræ: And the isoauroral diagram. Proc Indian Acad Sci 37(2): 175-188.

Cid C, Saiz E, Guerrero A, Palacios J, Cerrato Y. 2015. A Carrington-like geomagnetic storm observed in the 21 st century. J Space Weather Space Clim 5: A16, 1-6.

Garland GD. 1979. The contributions of Carl Friedrich Gauss to geomagnetism. Hist Math 6(1): 5-29.

Gauss CF. 1838. Bemerkungen über die Einrichtung und den Gebrauch des Bifilar-Magnetometers. In: Resultate aus den Beobachtungen des Magnetischen Vereins im Jahre 1837. Gauss
CF, Weber W (Eds.), Verlage der Dieterichschen Buchhandlung, Göttingen, pp. 20-37.

Green JL, Boardsen S. 2006. Duration and extent of the great auroral storm of 1859. Adv Space Res 38(2): 130-135.

Hayakawa H, Ebihara Y, Willis DM, Hattori K, Giunta AS, Wild MN, Hayakawa S, Toriumi S, Mitsuma Y, MacDonald LT, Shibata K, Silverman SM. 2018. The great space weather event during 1872 February recorded in East Asia. Astrophys $J$ 862: 1.

Hodgson R. 1860. On a curious appearance seen in the Sun. Mon Not Roy Astron Soc 20: 15.

Keika K, Ebihara Y, Kataoka R. 2015. What caused the rapid recovery of the Carrington storm? Earth Planets Space 61(1): art. no. 65 .

Kreil K, Jelinek K. 1850. Magnetische und meteorologische Beobachtungen zu Prag [Magnetic and meteorological observations in Prague]. Druck der k. k. Hofbuchdruckerei von Gottlieb Haase Söhne, Prag (Prague), Czech Republic. (In German).

Montbriand LE. 1970. A simple method for calculating the local time of corrected geomagnetic midnight. J Geophys Res Space Phys $\mathbf{7 5}$ (28): 5634-5636.

Moss NAF. 1910. Magnetic observations made at the Government Observatory, Bombay, for the period 1846 to 1905 and their discussion, Part II. The Phenomenon and its Discussion. Bombay Government Central Press, Bombay (present-day Mumbai), Maharashtra. Retrieved from http://www.geomag.bgs.ac.uk/data service/data/yearbooks/YBpdf/YB_CLA_1846-1905b.pdf.

Moreno Cárdenas F, Cristancho Sánchez S, Vargas Domínguez S. 2016. The grand aurorae borealis seen in Colombia in 1859. $A d v$ Space Res 57(1): 257-267.

Nevanlinna H. 1997. Gauss' H-variometer at the Helsinki Magnetic Observatory 1844-1912. J Geomag Geoelectr 49: 1209-1215.

Odenwald S. 2015. Solar storms: 2000 years of human calamity! CreateSpace Independent Publishing Platform, San Bernardino, CA, USA. ISBN-10: 1505941466, ISBN-13: 978-1505941463.

Shi Y, Zesta E, Lyons LR. 2008. Modeling magnetospheric current response to solar wind dynamic pressure enhancements during magnetic storms: 1 . Methodology and results of the 25 September 1998 peak main phase case. J Geophys Res: Space Phys 113(10): , $1-13$.

Silverman SM. 2008. Low-latitude auroras: The great aurora of 4 February 1872. J Atmos Solar-Terr Phys 70(10): 1301-1308.

Tanskanen EI, Pulkkinen TI, Koskinen HEJ, Slavin JA. 2002. Substorm energy budget during low and high solar activity: 1997 and 1999 compared. J Geophys Res: Space Phys 107(A6).

Tanskanen EI, Slavin JA, Fairfield DH, Sibeck DG, Gjerloev J, Mukai T, Ieda A, Nagai T. 2005. Magnetotail response to prolonged southward IMF bz intervals: Loading, unloading, and continuous magnetospheric dissipation. J Geophys Res: Space Phys 110(A3).

Tsyganenko NA, Sitnov MI. 2005. Modeling the dynamics of the inner magnetosphere during strong geomagnetic storms. J Geophys Res 110: A03208.

Tsurutani BT, Gonzalez WD, Lakhina GS, Alex S. 2003. The extreme magnetic storm of 1-2 September 1859. J Geophys Res: Space Phys 108(A7): art. no. 1268.

Van Baak DA. 2013. Re-creating Gauss's method for non-electrical absolute measurements of magnetic fields and moments. Am J Phys 81(10): 738-744. 


\section{Appendix}

\section{Supplementary data for the Clementinum storm}

Table A1. The digital data of the Clementinum storm, variations of the horizontal intensity and variations of the declination, recorded on 17 November 1848 by Kreil and Jelinek (1850). The first column in the table is the Göttingen Mean Solar Time (MST), which is 40 min ahead of the Greenwich MST and 18 min behind of the Clementinum MST.

\begin{tabular}{|c|c|c|c|c|c|c|c|c|}
\hline \multirow{2}{*}{$\begin{array}{l}\text { Göttingen } \\
\text { MST }\end{array}$} & \multicolumn{2}{|c|}{ Variations } & \multirow{2}{*}{$\frac{\text { Göttingen }}{\text { MST }}$} & \multicolumn{2}{|c|}{ Variations } & \multirow{2}{*}{$\frac{\text { Göttingen }}{\text { MST }}$} & \multicolumn{2}{|c|}{ Variations } \\
\hline & $H[\mathrm{nT}]$ & $D\left[^{\prime}\right]$ & & $H[\mathrm{nT}]$ & $D\left[^{\prime}\right]$ & & $H[\mathrm{nT}]$ & $D\left[{ }^{\prime}\right]$ \\
\hline 00:00:00 & 44.5 & -20.9 & 06:04:52 & 31.7 & -11.0 & $10: 41: 52$ & -321.0 & 38.3 \\
\hline $00: 06: 52$ & 46.9 & -20.8 & $06: 08: 52$ & 35.3 & -12.6 & $10: 45: 52$ & -326.6 & 41.3 \\
\hline 00:08:52 & 47.8 & -20.8 & $06: 10: 52$ & 33.9 & -13.8 & $10: 47: 52$ & -329.4 & 44.4 \\
\hline $00: 10: 52$ & 54.6 & -21.3 & $06: 12: 52$ & 18.9 & -14.8 & $10: 49: 52$ & -308.1 & 48.3 \\
\hline $00: 16: 52$ & 52.6 & -21.4 & $06: 18: 52$ & 7.5 & -17.8 & $10: 57: 52$ & -224.6 & 63.9 \\
\hline $00: 18: 52$ & 53.3 & -22.5 & 08:00:00 & -36.1 & 17.5 & $10: 59: 52$ & -219.0 & 64.3 \\
\hline $00: 20: 52$ & 53.0 & -21.7 & 09:55:00 & -223.8 & 15.9 & $11: 01: 52$ & -203.9 & 66.7 \\
\hline $00: 22: 52$ & 55.5 & -21.8 & 10:00:00 & -302.7 & 0.8 & $11: 03: 52$ & -186.7 & 66.9 \\
\hline 01:00:00 & 58.8 & -19.3 & $10: 03: 52$ & -309.6 & 0.4 & $11: 05: 52$ & -168.9 & 68.4 \\
\hline 01:55:00 & 5.9 & -6.8 & $10: 05: 52$ & -360.9 & 2.2 & $11: 07: 52$ & -141.7 & 69.8 \\
\hline 02:10:52 & 31.4 & -6.5 & $10: 15: 52$ & -362.0 & -9.0 & $11: 19: 52$ & -88.3 & 44.9 \\
\hline 03:55:00 & -7.2 & -29.5 & $10: 17: 52$ & -365.1 & -9.4 & $11: 21: 52$ & -95.5 & 41.6 \\
\hline 04:00:00 & 9.0 & -26.5 & $10: 19: 52$ & -398.9 & -13.2 & $11: 23: 52$ & -107.9 & 36.2 \\
\hline 04:04:52 & 9.2 & -31.6 & $10: 21: 52$ & -431.4 & -18.6 & $11: 25: 52$ & -110.4 & 32.6 \\
\hline $04: 06: 52$ & -0.7 & -33.5 & $10: 23: 52$ & -434.1 & -21.4 & $11: 27: 52$ & -111.4 & 32.4 \\
\hline 04:08:52 & -12.2 & -33.6 & $10: 25: 52$ & -434.8 & -17.2 & $11: 29: 52$ & -118.7 & 31.0 \\
\hline 04:10:52 & -23.2 & -31.3 & $10: 27: 52$ & -432.5 & -13.1 & $11: 31: 52$ & -126.2 & 32.0 \\
\hline $04: 12: 52$ & -27.3 & -27.8 & $10: 29: 52$ & -420.4 & -5.1 & $11: 33: 52$ & -121.8 & 32.5 \\
\hline $04: 14: 52$ & -25.8 & -23.1 & $10: 31: 52$ & -363.6 & 4.1 & 18:00:00 & -61.5 & -38.8 \\
\hline $04: 16: 52$ & -23.5 & -20.2 & $10: 33: 52$ & -337.9 & 15.1 & 20:00:00 & -10.8 & -8.4 \\
\hline 04:18:52 & -19.4 & -18.2 & $10: 35: 52$ & -352.3 & 27.5 & $22: 00: 00$ & 0.9 & -7.6 \\
\hline 05:55:00 & 14.6 & -13.9 & $10: 37: 52$ & -361.6 & 31.1 & 24:00:00 & -26.6 & -9.4 \\
\hline 06:00:00 & 26.6 & -12.5 & $10: 39: 52$ & -346.1 & 35.3 & & & \\
\hline
\end{tabular}

Cite this article as: Valach F, Hejda P, Revallo M \& Bochníček 2019. Possible role of auroral oval-related currents in two intense magnetic storms recorded by old mid-latitude observatories Clementinum and Greenwich. J. Space Weather Space Clim. 9, A11. 